\title{
Special Issue on Precision Dimensional Measurements
}

\author{
Kuang-Chao Fan $1,2, * \mathbb{B}$ and Liang-Chia Chen $2, *$ (i) \\ 1 School of Mechanical Engineering, Dalian University of Technology, 2 Linggong Rd., Dalian 116023, China \\ 2 Department of Mechanical Engineering, National Taiwan University, 1, Sec. 4, Roosevelt Rd., \\ Taipei 10617, Taiwan \\ * $\quad$ Correspondence: fan@ntu.edu.tw (K.-C.F.); lchen@ntu.edu.tw (L.-C.C.)
}

Received: 2 August 2019; Accepted: 6 August 2019; Published: 12 August 2019

\section{Introduction}

Precision dimensional measurements always play the critical role in workshop quality control. Although there are many instruments on the market suitable for a variety of measuring demands, such as lengths, angles, regular forms, free forms, and special geometries, not all products can be easily measured by current instruments and technologies. Some cutting-edge manufacturing processes have produced many difficult to measure parts, such as complex geometry, 3D forms, mini-to-micro-sized parts, ultrahigh precision, high aspect ratio, large-scaled, soft surface, variable reflectance surface, etc. Some new measurement sciences and technologies are urgently needed to cope with these demands.

Ever since this Special Issue was announced in May 2018, it has received a great attention and many positive responses from worldwide experts in measurement sciences and instrumentation, especially China. There were 87 papers submitted to this special issue, and 41 papers were accepted. Such a high acceptance rate reveals the good quality and interesting subjects contributed from authors of renowned universities and institutes. These published papers can be categorized into four main groups, including surface profile and form measurements, sensors and probes development, laser-based interferometer systems, and other measurement systems. Details are introduced in the following.

\section{Surface Profile and Form Error Measurements}

The first paper on 3D surface profile measurement is introduced by $\mathrm{Qu}$ and his colleagues at Beihang University on the measurement sensitivity of through-focus scanning optical microscopy (TSOM), which involves scanning a target through the focus and capturing of a series of images [1]. It was found that for enhanced sensitivity, illumination polarization should be perpendicular to the target texture. Professor Gao's group at Tohoku University presents a different method to increase Z-measurement range of 3D profile using mode-locked femtosecond laser chromatic confocal probe [2]. They also provide an uncertainty evaluation method for measurements of pitch deviation and out-of-flatness of planar scale gratings by a Fizeau Interferometer in Littrow configuration [3]. A collaborative work between Karlsruhe Institute of Technology of Germany and Ohio State University of USA presents a generalized approach using measurement data to enhance the simulation model for designing freeform optics [4]. The boundary of a surface is difficult to measure by normal microscopy. Professor Chen of National Taiwan University employed the digital image correlation (DIC) technique to assist accurate edge detection of 3D surface profilometry [5]. He also proposes a new moiré projection triangulation method using a dual optical sensing configuration by engaging two optical sensors at two different viewing angles for achieving simultaneous full-field surface profilometry for measuring semiconductor wafer surfaces with extremely variant reflectivities [6]. An international cooperative work by Shanghai University (Sun et al.), Nanyang Technological University (Asundi) and Linköping University (Valukh) presents the algorithm for surfaces profiles and thickness variation measurement of a transparent plate using a Fizeau interferometer with wavelength tuning [7]. Another 
useful algorithm of iterative stitching was also developed by this team on high numerical aperture cylindrical surface [8]. Li et al. proposes an innovative methodology of cloud data compression for free-form surface scanning measurement. It can save substantial data memory while remaining in good quality [9]. We are pleased to have the contribution by Professor Liu at HUST on the Mueller matrix technique for nanostructure scatterometry [10] and ellipsometry [11]. Li et al. deals with the method of measuring a large aspherical mirror and identifying its vertex position [12]. Liu et al. summarizes and compares the current five-point cylindricity error separation method with proximity sensors [13]. This provides a guideline for accurate evaluation of cylindricity errors.

\section{Sensors and Probes}

There are some papers focusing on the fabrication of new sensors and probes. Li's group at Hefei University of Technology successfully developed a chemical etching method to fabricate different shapes of leaf springs [14]. This is a key component of any touch-trigger probe on a coordinate measuring machine (CMM). Professor Tan's group at HIT (Harbin Institute of Technology) introduces a novel spherical scattering electrical-field contact probe [15]. This makes the measurement of ultraprecision diameter of small holes with large depth-to-diameter ratio possible. Image processing technique is often used in visual measurement. Camera calibration is a primary task to assure measurement accuracy. Zhao [16] and Yang [17] address respective methods to calibrate image pose sensors to subpixel level. An interesting time-grating capacitive displacement sensor is introduced by Professor Liu of Chongqing University of Technology [18]. It has the capability for absolute positioning based on a vernier-type structure. He et al. propose a real-time 3D shape reconstruction method of soft surgical actuator which has an embedded optical fiber with two Fiber Bragg Grating (FBG) sensors [19].

\section{Laser Interferometer Length Measurements}

The distance measurement based on various laser interferometer systems is a highlight of the Special Issue. This part includes incremental distance interferometer, absolute distance interferometer and grating diffraction interferometer. For the miniaturization of laser interferometer, a compact laser diode-based interferometer was developed by Cai et al. of Dalian University of Technology [20]. The wavelength cannot be determined by the Edlén Equation, which is mainly used for He-Ne lasers. Therefore, a grating diffraction method is employed to real-time detect the wavelength. Ren et al. from Tianjin University developed a different method to measure air refractive index based on the special material Etalon [21]. Professor Zhang's group of Tsinghua University describes the unique frequency-shifted optical feedback measurement technologies using a solid-state microchip laser [22]. In the area of absolute distance measurement, the frequency scanning (FS) laser is the main laser source. Xiong et al. calculated the effective center wavelength for heterodyne interferometry of an optical frequency comb [23]. Gao et al. propose a technique to compensate the FS interferometer [24] and Xiong et al. propose an adaptive filtering method to correct errors due to interfering signals of FS interferometer [25]. In the area of grating diffraction-based interferometer, a double diffraction heterodyne interferometer was developed by Chang [26]. Li et al. of Tsinghua University designed two innovate key components for planar grating interferometers, namely the Lloy's mirror [27] and the prism module [28].

\section{CMM and Machine Tool Error Measurements}

Coordinate measuring machines (CMMs) provide 3D measurement capability with probes. Cheng et al. evaluated and optimized task-oriented measurement uncertainty for CMMs based on geometrical product specifications [29]. Gaska et al. searched the optimal path control algorithm for probe heads used on five-axis CMMs [30]. Wu et al. developed on-machine optical measuring equipment for drilled holes [31].

There are some reports on the geometrical error measurement of machine tools. Professor Jywe's group of National Formosa University developed a geometric error measurement system to assist 
the linear guideway assembly process [32]. Professor Feng's group of Beijing Jiaotong University propose a simultaneous six-degree-of-freedom error measurement system for rotary stages [33]. Wang considered a hybrid optimization method to optimize the power consumption during CNC (computer numerically cntrolled) milling process [34].

\section{Other Measurement Systems}

In addition to dimensional measurements, there are some other purposes of measurement. Because they are interesting, we also consider the following for inclusion in this Special Issue. Wang studied the biomechanical feedback system in training of hammer-throw [35]. A wearable inertia measurement unit has been developed that could help obtain the vital distance. An efficient real-time tunnel deformation monitoring technology based on laser and machine vision was developed by Qiu et al. [36]. In the large-scale metrology, Shi et al. use photoelectric scanning measurement network to model dynamic errors [37]. Wang designed a structure for accurately determining the mass and center of gravity of rigid bodies [38]. Yang et al. developed non-contact and real-time measurement of high strain rate Kolsky bar with temporal speckle interferometry [39]. Zhang et al. present a demodulation technique for weak photo-acoustic signals of laser interferometer on water surface [40]. The last paper was written by Qiu et al. on the experimental analyses on multiscale structural and mechanical properties of $\varepsilon-\mathrm{Si} / \mathrm{GeSi} / \mathrm{C}-\mathrm{Si}$ materials [41]. Strained silicon $(\varepsilon-\mathrm{Si})$ is a promising material that could extend Moore's law by enhancing electron mobility. The layer components and thicknesses were measured using energy-dispersive spectroscopy and scanning-electron microscopy. Crystal and lattice characters were observed by using high-resolution transmission-electron microscopy and micro-Raman spectroscopy.

Acknowledgments: This issue would not be successful without the contributions of earnest authors, professional reviewers, and dedicated editorial team of Applied Sciences. We are grateful to all authors, who spent time to prepare the manuscript and respond comments from the reviewers, no matter what the final decisions of the submitted manuscripts were. Special thanks also to all reviewers, who always provided fast and responsible services to the requests. Finally, we take this opportunity to express our gratitude to the editorial team of Applied Sciences, and special thanks to Daria Shi, and Xiaoyan Chen both from MDPI Branch Office, Beijing.

Conflicts of Interest: The authors declare no conflict of interest.

\section{References}

1. Qu, Y.; Peng, R.; Hao, J.; Pan, H.; Niu, J.; Jiang, J. Influence of Illumination Polarization and Target Structure on Measurement Sensitivity of Through-Focus Scanning Optical Microscopy. Appl. Sci. 2018, 8, 1819. [CrossRef]

2. Chen, C.; Sato, R.; Shimizu, Y.; Nakamura, T.; Matsukuma, H.; Gao, W. A Method for Expansion of Z-Directional Measurement Range in a Mode-Locked Femtosecond Laser Chromatic Confocal Probe. Appl. Sci. 2019, 9, 454. [CrossRef]

3. Xiong, X.; Shimizu, Y.; Chen, X.; Matsukuma, H.; Gao, W. Uncertainty Evaluation for Measurements of Pitch Deviation and Out-of-Flatness of Planar Scale Gratings by a Fizeau Interferometer in Littrow Configuration. Appl. Sci. 2018, 8, 2539. [CrossRef]

4. Sieber, I.; Yi, A.; Gengenbach, U. Metrology Data-Based Simulation of Freeform Optics. Appl. Sci. 2018, 8, 2338. [CrossRef]

5. Chen, L.; Liang, C. Novel Boundary Edge Detection for Accurate 3D Surface Profilometry Using Digital Image Correlation. Appl. Sci. 2018, 8, 2541. [CrossRef]

6. Chen, L.; Duong, D.; Chen, C. Optical 3-D Profilometry for Measuring Semiconductor Wafer Surfaces with Extremely Variant Reflectivities. Appl. Sci. 2019, 9, 2060. [CrossRef]

7. Sun, T.; Zheng, W.; Yu, Y.; Yan, K.; Asundi, A.; Valukh, S. Algorithm for Surfaces Profiles and Thickness Variation Measurement of a Transparent Plate Using a Fizeau Interferometer with Wavelength Tuning. Appl. Sci. 2019, 9, 2349. [CrossRef]

8. Chen, D.; Peng, J.; Valyukh, S.; Asundi, A.; Yu, Y. Measurement of High Numerical Aperture Cylindrical Surface with Iterative Stitching Algorithm. Appl. Sci. 2018, 8, 2092. [CrossRef] 
9. Li, Y.; Ma, Y.; Tao, Y.; Hou, Z. Innovative Methodology of On-Line Point Cloud Data Compression for Free-Form Surface Scanning Measurement. Appl. Sci. 2018, 8, 2556. [CrossRef]

10. Chen, C.; Chen, X.; Shi, Y.; Gu, H.; Jiang, H.; Liu, S. Metrology of Nanostructures by Tomographic Mueller-Matrix Scatterometry. Appl. Sci. 2018, 8, 2583. [CrossRef]

11. Jiang, H.; Ma, Z.; Gu, H.; Chen, X.; Liu, S. Characterization of Volume Gratings Based on Distributed Dielectric Constant Model Using Mueller Matrix Ellipsometry. Appl. Sci. 2019, 9, 698. [CrossRef]

12. Li, J.; Yan, F.; Chen, L.; Yang, J.; Wan, Y. Measurement Vertex Position of a Large Aspheric Mirror. Appl. Sci. 2019, 9, 1038. [CrossRef]

13. Liu, W.; Hu, P.; Fan, K. Comparison of Current Five-Point Cylindricity Error Separation Techniques. Appl. Sci. 2018, 8, 1946. [CrossRef]

14. Li, R.; Wang, P.; Li, D.; Fan, K.; Liu, F.; Chen, L.; Huang, Q. Precision Manufacturing of Patterned Beryllium Bronze Leaf Springs via Chemical Etching. Appl. Sci. 2018, 8, 1476. [CrossRef]

15. Bian, X.; Cui, J.; Lu, Y.; Tan, J. Ultraprecision Diameter Measurement of Small Holes with Large Depth-To-Diameter Ratios Based on Spherical Scattering Electrical-Field Probing. Appl. Sci. 2019, 9, 242. [CrossRef]

16. Zhao, N.; Sun, C.; Wang, P. Calibration Method of Orthogonally Splitting Imaging Pose Sensor Based on General Imaging Model. Appl. Sci. 2018, 8, 1399. [CrossRef]

17. Yang, T.; Zhao, Q.; Wang, X.; Zhou, Q. Sub-Pixel Chessboard Corner Localization for Camera Calibration and Pose Estimation. Appl. Sci. 2018, 8, 2118. [CrossRef]

18. Liu, X.; Zhang, H.; Peng, K.; Tang, Q.; Chen, Z. A High Precision Capacitive Linear Displacement Sensor with Time-Grating that Provides Absolute Positioning Capability Based on a Vernier-Type Structure. Appl. Sci. 2018, 8, 2419. [CrossRef]

19. He, Y.; Zhu, L.; Sun, G.; Yu, M.; Dong, M. Design, Measurement and Shape Reconstruction of Soft Surgical Actuator Based on Fiber Bragg Gratings. Appl. Sci. 2018, 8, 1773. [CrossRef]

20. Cai, Y.; Lou, Z.; Ling, S.; Liao, B.; Fan, K. Development of a Compact Three-Degree-of-Freedom Laser Measurement System with Self-Wavelength Correction for Displacement Feedback of a Nanopositioning Stage. Appl. Sci. 2018, 8, 2209. [CrossRef]

21. Ren, G.; Qu, X.; Ding, S. A Real-Time Measurement Method of Air Refractive Index Based on Special Material Etalon. Appl. Sci. 2018, 8, 2325. [CrossRef]

22. Zhu, K.; Chen, H.; Zhang, S.; Shi, Z.; Wang, Y.; Tan, Y. Frequency-Shifted Optical Feedback Measurement Technologies Using a Solid-State Microchip Laser. Appl. Sci. 2019, 9, 109. [CrossRef]

23. Xiong, S.; Yang, Z.; Leo, L.; Wu, G. Calculating the Effective Center Wavelength for Heterodyne Interferometry of an Optical Frequency Comb. Appl. Sci. 2018, 8, 2465. [CrossRef]

24. Gao, S.; Ji, R.; Li, Y.; Liu, C.; Shi, J.; Pan, Y.; Zhou, W. Compensation of Frequency Drift in Frequency-Sweep Polarization-Modulation Ranging System. Appl. Sci. 2019, 9, 1243. [CrossRef]

25. Xiong, X.; Qu, X.; Zhang, F. Error Correction for FSI-Based System without Cooperative Target Using an Adaptive Filtering Method and a Phase-Matching Mosaic Algorithm. Appl. Sci. 2018, 8, 1954. [CrossRef]

26. Chang, D.; Xing, X.; Hu, P.; Wang, J.; Tan, J. Double-Diffracted Spatially Separated Heterodyne Grating Interferometer and Analysis on its Alignment Tolerance. Appl. Sci. 2019, 9, 263. [CrossRef]

27. Li, X.; Lu, H.; Zhou, Q.; Wu, G.; Ni, K.; Wang, X. An Orthogonal Type Two-Axis Lloyd's Mirror for Holographic Fabrication of Two-Dimensional Planar Scale Gratings with Large Area. Appl. Sci. 2018, 8, 2283. [CrossRef]

28. Li, X.; Shi, Y.; Xiao, X.; Zhou, Q.; Wu, G.; Lu, H.; Ni, K. Design and Testing of a Compact Optical Prism Module for Multi-Degree-of-Freedom Grating Interferometry Application. Appl. Sci. 2018, 8, 2495. [CrossRef]

29. Cheng, Y.; Wang, Z.; Chen, X.; Li, Y.; Li, H.; Li, H.Y.; Wang, H. Evaluation and Optimization of Task-oriented Measurement Uncertainty for Coordinate Measuring Machines Based on Geometrical Product Specifications. Appl. Sci. 2019, 9, 6. [CrossRef]

30. Gaska, A.; Gaska, P.; Gruza, M.; Sładek, J. Selection of Optimal Path Control Algorithms for Probe Heads Used on Five-Axis Measuring Systems. Appl. Sci. 2018, 8, 2455. [CrossRef]

31. Wu, N.; Zhao, W.; Wang, X.; Tao, Y.; Hou, Z. A Novel Design of Through-Hole Depth On-Machine Optical Measuring Equipment for Automatic Drilling and Riveting. Appl. Sci. 2018, 8, 2671. [CrossRef]

32. Hsieh, T.; Chen, P.; Jywe, W.; Chen, G.; Wang, M. A Geometric Error Measurement System for Linear Guideway Assembly and Calibration. Appl. Sci. 2019, 9, 574. [CrossRef] 
33. Bao, C.; Feng, Q.; Li, J. Simultaneous Measurement Method and Error Analysis of the Six Degrees-of-Freedom Motion Errors of a Rotary Axis. Appl. Sci. 2018, 8, 2232. [CrossRef]

34. Wang, S.; Lee, C.; Gunawan, H.; Yeh, C. An Accuracy-Efficiency-Power Consumption Hybrid Optimization Method for CNC Milling Process. Appl. Sci. 2019, 9, 1495. [CrossRef]

35. Wang, Y.; Li, H.; Wan, B.; Zhang, X.; Shan, G. Obtaining Vital Distances Using Wearable Inertial Measurement Unit for Real-Time, Biomechanical Feedback Training in Hammer-Throw. Appl. Sci. 2018, 8, 2470. [CrossRef]

36. Qiu, Z.; Li, H.; Hu, W.; Wang, C.; Liu, J.; Sun, Q. Real-Time Tunnel Deformation Monitoring Technology Based on Laser and Machine Vision. Appl. Sci. 2018, 8, 2579. [CrossRef]

37. Shi, S.; Yang, L.; Lin, J.; Long, C.; Deng, R.; Zhang, Z.; Zhu, J. Dynamic Measurement Error Modeling and Analysis in a Photoelectric Scanning Measurement Network. Appl. Sci. 2019, 9, 62. [CrossRef]

38. Wang, M.; Zhang, X.; Tang, W.; Wang, J. A Structure for Accurately Determining the Mass and Center of Gravity of Rigid Bodies. Appl. Sci. 2019, 9, 2532. [CrossRef]

39. Yang, S.; Gao, Z.; Ruan, H.; Gao, C.; Wang, X.; Sun, X.; Wen, X. Non-Contact and Real-Time Measurement of Kolsky Bar with Temporal Speckle Interferometry. Appl. Sci. 2018, 8, 808. [CrossRef]

40. Zhang, X.; Mao, H.; Tang, W. Demodulation Technique Based on Laser Interference for Weak Photo-Acoustic Signals on Water Surface. Appl. Sci. 2018, 8, 2423. [CrossRef]

41. Qiu, W.; Ma, L.; Wang, H.; Liang, R.; Zhao, Y.; Zhou, Y. Experimental Analyses on Multiscale Structural and Mechanical Properties of $\varepsilon$-Si/GeSi/C-Si Materials. Appl. Sci. 2018, 8, 2333. [CrossRef]

(C) 2019 by the authors. Licensee MDPI, Basel, Switzerland. This article is an open access article distributed under the terms and conditions of the Creative Commons Attribution (CC BY) license (http://creativecommons.org/licenses/by/4.0/). 